\title{
COMUNIDADES QUILOMBOLAS: discursos e disputas por direitos territoriais ${ }^{1}$
}

\section{QUILOMBOLA COMMUNITIES: speeches and disputes over territorial rights}

COMUNIDADES QUILOMBOLAS: discursos y disputas por derechos territoriales

Amanda Lacerda Jorge

Doutora em Política Social e Doutoranda em Sociologia

Universidade Federal Fluminense amandalacerda@id.uff.br

Brasil

ORCID 0000-0003-3005-9233

André Augusto Pereira Brandão

Doutor em Ciências Sociais

Universidade Federal Fluminense

andre_brandao@id.uff.br

Brasil

ORCID 0000-0002-9245-0273

\section{Resumo}

$\mathrm{Na}$ busca por contribuir com maiores reflexões no que se refere ao direito territorial de povos e comunidades tradicionais como quilombolas, este artigo pretende discutir sobre a disputa interpretativa no campo do direito acerca da titulação e demarcação dos territórios que pertencem a estes grupos. O estudo aborda a Ação Direta de Inconstitucionalidade (ADI) no 3239/2004 (movida pelo Partido Democratas contra o Decreto n ${ }^{\circ} 4887 / 2003$ ) que regulamenta o processo de titulação territorial das comunidades quilombolas. Ao mobilizar um número elevado de agentes internos e externos ao campo jurídico, a ADI no 3239/2004 teve longa tramitação no Supremo Tribunal Federal

\footnotetext{
${ }^{1}$ Paper originalmente apresentado no Grupo de Trabalho 17, intitulado «Processos de reconhecimento de direitos, mediação intercultural e disputas territoriais no Brasil contemporâneo», do VI ENADIR (Encontro Nacional de Antropologia do Direito), ocorrido entre 26 e 29 de agosto de 2019 na FFLCH-USP (Faculdade de Filosofia, Letras e Ciências Humanas da Universidade de São Paulo).
} 
com alto grau de exposição de conflitos interpretativos, os quais foram finalizados no julgamento final, ocorrido no mês de fevereiro de 2018. Tal panorama trouxe perplexidade e novas indagações ao campo do direito e à sociedade em geral ao colocar em cena questões relacionadas a garantia do direito fundamental à vida, reprodução material, cultural, social e simbólica destes povos.

Palavras chave: Povos e comunidades Tradicionais, Território, Quilombos, Supremo Tribunal Federal

\begin{abstract}
In the quest to contribute to reflections on the territorial law of traditional peoples and communities such as quilombolas, this article aims to discuss the interpretive dispute in the legal field about the title and demarcation of the territories that belong to these groups. The study addresses the Direct Action of Unconstitutionality (ADI) 3239/2004 brought by the Democratic Party against Decree No. 4887/2003 (which regulates the process of territorial titling of quilombola communities). The proposed investigation was based on a bibliographic survey and mainly on the documentary analysis of the records of the trial process. By mobilizing a large number of internal and external agents in the legal field, ADI 3239/2004 had a long process in the Supreme Federal Court, with a high degree of exposure to interpretive conflicts, which were finalized in the final judgment, which occurred in February 2018. The context in question brought perplexity and new questions to the field of law and to society in general, putting on the scene issues related to the guarantee of the fundamental right to life, the material, cultural, social and symbolic reproduction of these peoples.
\end{abstract}

Keywords: Traditional Peoples and Communities, Territory, Quilombos, Supreme Federal Court.

\title{
Resumen
}

En la búsqueda de contribuir a las reflexiones sobre el derecho territorial de los pueblos y comunidades tradicionales como los quilombolas, este artículo tiene como objetivo discutir la disputa interpretativa en el campo legal sobre el título y demarcación de los territorios que pertenecen a estos grupos. El estudio aborda la Acción Directa de Inconstitucionalidad (ADI) 3239/2004 interpuesta por el Partido Demócrata contra el Decreto No. 4887/2003 (que regula el proceso de titulación territorial de las comunidades quilombolas). La investigación propuesta se basó en un relevamiento bibliográfico y principalmente en el análisis documental de los registros del proceso judicial. Al movilizar a un gran número de agentes internos y externos en el ámbito legal, ADI 3239/2004 tuvo un largo proceso en el Supremo Tribunal Federal, con un alto grado de exposición a conflictos interpretativos, los cuales fueron concretados en la sentencia firme, ocurrida en febrero. 2018. El contexto en cuestión trajo perplejidad y nuevos interrogantes al campo del derecho y a la sociedad en general, poniendo en escena temas relacionados con la garantía del derecho fundamental a la vida, la reproducción material, cultural, social y simbólica de estos pueblos.

Palabras clave: Pueblos y comunidades tradicionales, Territorio, Quilombos, Tribunal Supremo Federal 
"questão quilombola" que vem
se constituindo desde 1988 no
Brasil, a partir de discursos e posições de vários agentes e agências, não existia antes do próprio artigo 68 do Ato das Disposições Constitucionais Transitórias (ADCT), no qual, pela primeira vez, o Estado assume compromissos redistributivos com as "comunidades negras rurais". Com este aparato jurídico foi garantido constitucionalmente o direito à propriedade da terra para este heterogêneo grupo. No entanto, a imprecisão do artigo 68 do ADCT gerou um intenso debate sobre os limites e possibilidades de operacionalização e fruição deste acesso à propriedade fundiária. É no bojo desta contenda, que presenciamos a abertura de várias janelas de interpretação, fundadas sobre - e apontando para concepções e pontos de vista diferenciados sobre essas comunidades e seus direitos.

É diante deste cenário que o presente artigo se situa: a partir das discursividades ${ }^{2}$ que alimentam até os dias atuais o que chamamos de "questão quilombola", buscaremos compreender como esta "problemática" vem sendo construída e interpretada por práticas discursivas tecidas no campo judiciário brasileiro. Para tanto, temos como foco principal a movimentação institucional em

\footnotetext{
2 A partir de Bourdieu (2003), definimos "discursividades como a prática social relativa à emissão de evocações que têm potencialidade para constituir institucionalmente,
}

torno da Ação Direta de Inconstitucionalidade (ADI) $\mathrm{n}^{\circ} 3.239$ de 2004, proposta contra o Decreto $n^{\circ} 4.887 / 2003$ no Supremo Tribunal Federal (STF).

Ao mobilizar um número elevado de agentes internos e externos no campo jurídico, a ADI no 3239/2004 teve longa tramitação no Supremo Tribunal Federal, com alto grau de exposição de conflitos interpretativos, os quais chegaram a termo no julgamento final ocorrido no mês de fevereiro de 2018. Percebe-se que as discursividades esgrimidas no campo do judiciário se relacionam diretamente com saberes especializados produzidos no campo da antropologia, seja para negá-los, seja para buscar apoio. No caso da "questão quilombola", o conjunto de discursividades que analisaremos foi responsável por construir - ainda que sob oposição e travando uma forte luta classificatória - uma "verdade" acerca de quem são os "remanescentes de quilombos", quais são seus direitos, e como o Estado deve se relacionar com ambos. Vejamos.

\section{A questão quilombola}

Os "remanescentes de quilombos" trazem para o cenário rural novas

socialmente, simbolicamente e juridicamente sujeitos e mesmo "problemas sociais". 
perspectivas para as comunidades que historicamente eram nomeadas como "rurais negras" ou "terras de preto". Uma das pautas principais destes povos é a luta pelo reconhecimento de direitos coletivos e sociais, tomando como base o amparo constitucional previsto pelo artigo 68 do ADCT da Constituição Federal de 1988. O cenário de luta destas comunidades tradicionais é marcado por avanços e retrocessos, contradições e defesas, e traz a participação de movimentos sociais, legisladores, operadores do direito, agentes estatais, antropólogos e as próprias comunidades "quilombolas". Todos estes colaboram na construção de uma teia de interpretações que alimentam a existência da “questão quilombola” no Brasil.

A produção destes novos sujeitos políticos de forma socialmente legítima, diferenciados pela denominação "quilombola", tem início portanto a partir da emissão do artigo 68 do ADCT. Este dispositivo corresponde ao reconhecimento público da existência de um grupo específico. Mas este, logo de início, apresentou pressupostos confusos e indefinidos. Isto porque o artigo 68 do ADCT teria sido incorporado à Constituição "em uma formulação 'amputada' e, mesmo assim, apenas em função de intensas negociações políticas levadas por representantes do movimento negro do Rio de Janeiro"
(ARRUTI, 2006, p. 67). Tal contexto ocorreu durante a Assembleia Nacional Constituinte, que acabou englobando, também, propostas da sociedade civil e de movimentos sociais. A questão fundamental que Arruti (2006) procura mostrar na gênese da nova categoria social "quilombola" é a improvisação de um direito que se voltou para a questão fundiária de "agrupamentos negros rurais", sem ao menos se entender quais seriam as demandas, e de fato quem seriam estes sujeitos.

O artigo 68 do ADCT teria, portanto, uma forma "amputada", ao ser aprovado sem maiores discussões, tendo como "caldo ideológico" o Centenário da Abolição. É daí, que o termo "remanescentes de quilombos" toma forma, ligando os grupos de negros do meio rural do momento presente, com o passado histórico de Zumbi dos Palmares. O que percebemos é que o contexto político e social da década de 1980, influenciou a criação do artigo 68 do ADCT. E, apesar das mobilizações e vocalizações terem inicialmente como cena o contexto urbano, o movimento negro, ativistas, cientistas sociais e intelectuais também acabaram entrando no campo dos conflitos fundiários ligados as inicialmente nomeadas "comunidades negras rurais". Essas comunidades que começaram a ser mapeadas já no início da década de 1980 nos estados do Maranhão e Pará pelo Movimento Negro da região tiveram as suas demandas vocalizadas no mês de agosto de 
1986 através da $1^{\text {a }}$ Convenção Nacional do Negro pela Constituinte.

Em atendimento a convocatória nacional, para que vários segmentos da sociedade pudessem contribuir na construção da Carta Magna, representantes de 63 entidades ligados as questões raciais participaram conjuntamente dessa Convenção. A Convenção organizou em um documento, reinvindicações que foram enviadas em 1987 para a Assembleia Nacional Constituinte. No documento, o grupo de participantes esclarece que a "denominação de negros engloba todos aqueles que possuem caracteres, fenótipos, e ou genótipos, dos povos africanos que aqui foram trazidos para o trabalho escravo" (CONVENÇÃO NACIONAL DO NEGRO, 1986, p. 1), e propõem um leque de direitos presentes em várias esferas como saúde, educação e segurança.

No título "sobre a questão da terra", elaborado pela Convenção, é possível encontrar a primeira demanda por titulação territorial para a população negra, tanto no contexto urbano quanto rural, e parece ser, no rol de nossas pesquisas, a primeira referência aos "quilombolas". No texto, aparece grafado: "será garantido o título de

\footnotetext{
${ }^{3}$ As discussões do novo texto constitucional na Assembleia Nacional Constituinte tiveram início nas 24 Subcomissões Temáticas, agrupadas em 8 Comissões. Após aprovados nas Subcomissões, os textos seguiram para as Comissões Temáticas respectivas, onde foram elaborados os capítulos por temas. Os três anteprojetos de cada Subcomissão foram
}

propriedade da terra às comunidades negras remanescentes de quilombos, quer no meio urbano ou rural" (CONVENÇÃO NACIONAL DO NEGRO, 1986, p. 6). Em fevereiro de 1987, instalou-se no Brasil a Assembleia Nacional Constituinte ${ }^{3}$ e $\operatorname{logo}$ após, em abril, foram formadas Subcomissões Temáticas. É possível encontrar na Subcomissão dos Negros, Populações Indígenas, Pessoas Deficientes e Minorias os primeiros apontamentos responsáveis por construir, mais tarde, o dispositivo voltado para os "quilombolas".

As questões relacionadas à definição de critérios de identificação e titulação das comunidades citadas no artigo 68 do ADCT foram os primeiros pontos a serem alvo de discussão de vários agentes e agências que buscavam uma forma de operacionalizar este dispositivo constitucional, principalmente a partir da década de 1990. O campo de debates contou com a participação de legisladores (com a formulação de anteprojetos de lei visando regulamentar o artigo 68 do ADCT), e instituições governamentais como a Fundação Cultural Palmares, o Ministério da Cultura e o Ministério do Desenvolvimento Agrário (MDA) através do Instituto Nacional de Colonização e Reforma Agrária (INCRA) -

reunidos em um anteprojeto único e, em seguida, transformado em um Anteprojeto de Comissão. Disponível em: $\quad<$ http://www2.camara.leg.br/atividadelegislativa/legislacao/Constituicoes_Brasileiras/constituica o-cidada/o-processo-constituinte>. Acesso em 20-07-2019. 
todos criando diretrizes e procedimentos para o reconhecimento territorial das comunidades.

Além da presença destes, o campo de discussões e interpretações sobre a "questão quilombola" também contou com a participação do Movimento Negro (no que diz respeito à pressão sobre o Estado pela efetivação do artigo 68 do ADCT), e com a presença de antropólogos. Este último grupo foi o responsável por contribuições no plano conceitual e científico. A teia de discussões que estava sendo construída na década de 1990, se sustentava em pontos que já haviam sido refletidos durante a consolidação de direitos voltados para os "remanescentes indígenas". O objetivo era tirar partido das:

Relações (materiais, simbólicas e analógicas) entre populações indígenas e populações negras, seja enquanto chaves classificatórias, seja enquanto populações históricas submetidas/rebeladas, ou enquanto novos sujeitos políticos criadores de cultura (ARRUTI, 1997, p.9).

Isto porque, a inclusão dos indígenas no código de direitos do Estado, também passou por discussões sobre a imprecisão de designa-los como ancestrais daqueles indígenas do início da história do Brasil. Foi neste momento, que a fórmula "remanescente" se fez presente, para classificar a presença do "estado de índio" nos grupos indígenas existentes na

\footnotetext{
${ }^{4}$ Segundo Almeida (1989), a denominação "comunidades negras rurais" não era única, os grupos se autoatribuíam outras denominações de acordo com as características de
}

modernidade, reconhecendo perdas culturais, mas, não negando o seu direito a ter direitos (ARRUTI, 1997). A partir da noção de "remanescentes indígenas", grupos que estavam desarticulados, em parte espalhados pelas periferias de cidades grandes e médias - principalmente no nordeste brasileiro - puderam se articular em movimentos e reivindicar territórios que teriam pertencido a seus ancestrais. Assim, como no caso dos indígenas, a presença do dispositivo discursivo "remanescentes", presente no artigo 68 do ADCT não foi suficiente para viabilizar, por si só a efetivação do direito à terra.

Foi necessário “ressignificar" este termo e, no mesmo movimento, "ressemantizar" o conceito para que este se tornasse adequado às formas contemporâneas dos "quilombos". A alteração da perspectiva que alicerçava pesquisas e trabalhos etnográficos a partir da década de 1980, abriu novos campos de análise e criou novas categorias relativas ao que ficamos conhecendo como "comunidades negras rurais ${ }^{4}$ ". Caracterizadas como unidades de cultura que possuíam traços próprios no seu modo de viver, e que partilhavam uma ancestralidade comum, essas comunidades já vinham sendo contabilizadas principalmente nos estados

cada local e formação, mas, teriam como ponto em comum o uso do território de maneira coletiva. 
do Maranhão e Pará. Desenhar as "comunidades negras rurais" por essa nova perspectiva, produziu elementos que colaboraram para vocalizar e visibilizar estes grupos frente à sociedade e ao Estado brasileiro. Ao receber este discurso que carregava uma nova classificação parte das comunidades anteriormente pensadas como "negras rurais" passariam a acionar a identidade "quilombola", que até há pouco tempo elas próprias desconheciam.

\section{O Supremo Tribunal Federal e a Ação Direta de Inconstitucionalidade $n^{0}$ 3239/2004}

O Decreto $\mathrm{n}^{\circ} 4.887 / 2003$ marca um ponto de inflexão fundamental na breve história da "questão quilombola". Este indica uma direta adesão do executivo federal às discursividades acerca do artigo 68 do ADCT que vinham sendo produzidas no campo da ciência social brasileira (em especial da antropologia) e utilizadas pelo movimento "quilombola" nascente. Esta "adesão" colocou de ponta a cabeça o formato legal anterior da definição do que seriam os "quilombolas" (que estava consolidada no Decreto $\mathrm{n}^{\circ} 3.912 / 2001$ no governo de Fernando Henrique Cardoso - FHC) e ampliou de forma significativa o quantitativo de comunidades que agora poderiam reivindicar o direito à titulação de seus territórios. O primeiro efeito do Decreto em tela é, portanto, desvincular os "quilombolas" da necessidade de uma comprovação que remeta a um passado de fuga de escravos. Indo mais longe, a caracterização destes sujeitos passa a ser atestada através da "autodefinição da própria comunidade" (artigo $2^{\circ}, \S 1^{\circ}$ do Decreto $n^{\circ} 4.887 / 2003$ ).

O Decreto também amplia potencialmente - a quantidade de hectares de terra que seriam utilizados para a titulação. Isto porque, define em seu $\S 2^{\circ}$ que seriam consideradas "terras ocupadas por remanescentes das comunidades dos quilombos as utilizadas para a garantia de sua reprodução física, social, econômica e cultural". Bem diferente disto, no Decreto anterior que regulava a matéria (Decreto $\mathrm{n}^{\circ}$ 3.912/2001 FHC), a possibilidade de titulação somente poderia englobar "terras que: I - eram ocupadas por quilombolas em 1888; e II - estavam ocupadas por remanescentes das comunidades dos quilombos em 5 de outubro de 1988."

A interpretação do artigo 68 do ADCT contida no Decreto $n^{\circ} 4.887 / 2003$ promove, portanto, uma dupla ampliação seja no rol de possíveis beneficiários, seja no montante de terras a serem tituladas. Acontece que este movimento vai gerar, quase imediatamente, uma resposta por parte daqueles que desde 1988, vinham buscando legitimar uma leitura mais restrita do 
dispositivo constitucional. De fato, temos aqui um embate direto entre duas concepções que estão contidas na chamada "sociedade aberta de intérpretes do texto constitucional" (HABERLE, 1997) e que colaboram - ainda que sob diferentes perspectivas - para a construção da "questão quilombola”. Assim, em junho de 2004, sete meses e três dias após a assinatura do Decreto $\mathrm{n}^{\circ} 4.887 / 2003$ este foi alvo de uma Ação Direta de Inconstitucionalidade (ADI) movida junto ao Supremo Tribunal Federal, pelo então Partido da Frente Liberal (PFL), atualmente denominado Democratas.

Inicia-se a partir deste ponto, um embate fundamental entre duas interpretações do artigo 68 do ADCT no cerne do campo do direito: seriam as comunidades quilombolas um patrimônio histórico formado por resquícios arqueológicos, ou seriam estes grupos étnico-identitários? Os agentes que promovem cada uma destas verdades se mobilizarão em torno da ação de inconstitucionalidade conhecida como ADI ${ }^{\circ}$ 3.239/2004. A Petição Inicial que dá início à ação movida no STF pelo Partido Democratas é relativamente sucinta, trata-se de 15 laudas somente. $\mathrm{O}$ documento que pretende arguir a inconstitucionalidade do Decreto $\mathrm{n}^{\mathrm{o}}$ 4.887/2003 junto ao Supremo Tribunal Federal no ano de 2004, procura construir uma determinada interpretação do texto constitucional (referente ao artigo 68 do
ADCT) e mesmo estabelecer uma definição do que seriam os "remanescentes de quilombos". Partindo de uma pressuposição relativa ao que seriam os quilombolas, o texto arguiu a inconstitucionalidade da forma elegida pelo Decreto $n^{\circ} 4.887 / 2003$ para definir os "titulares do direito à propriedade definitiva".

A pressuposição à qual nos referimos é que a "característica de remanescente das comunidades quilombolas" seria "rara" (PETIÇÃO INICIAL DA ADI No 3.239/2004, 2004, p. 8). Ou seja, ancorada numa interpretação cronológica, a Petição intui que seria "raro" encontrar atualmente estes grupos. Portanto, garantir a possibilidade de que as comunidades se autodefinissem como "quilombolas" equivaleria a substituir uma definição histórica, por uma "mera manifestação de vontade do interessado" (PETIÇÃO INICIAL DA ADI No 3.239/2004, 2004, p. 8). Assim, a categoria "quilombola", com a qual a Petição dialoga, se refere a reminiscências de um dado período cronologicamente definido. Mais especificamente, passando ao largo de toda a argumentação construída no Brasil desde 1994 no campo das ciências sociais (e em específico da antropologia) a Petição Inicial insiste na nomeação dos "remanescentes" como resquício histórico, que demanda comprovação para que haja presunção de direito. 
Percebe-se que não há um esforço em refutar as perspectivas que ressemantizaram as categorias "quilombo", "quilombola" e "remanescente"; e que representam também, é claro, uma forma específica de construir a "questão". Esta ressemantização é desconsiderada pela Petição Inicial, em um movimento argumentativo que parece propositalmente voltado para o não reconhecimento de qualquer emissão discursiva que não esteja vinculada a uma leitura do "quilombo" como produto da história colonial e imperial do Brasil. O que nos remete à ideia do "quilombo frigorificado" e arqueológico. A necessidade de comprovação é fundamental no arcabouço intelectual que sustenta a Petição da ADI no 3.239/2004. Se as comunidades quilombolas remetem ao período colonial e ao período imperial da história brasileira, será necessário comprovar que um determinado grupo "remanesce" de eventos ocorridos neste passado. Isto porque, na perspectiva dos autores da Petição, as comunidades quilombolas seriam aquelas "formadas por escravos fugidos, ao tempo da

\footnotetext{
${ }^{5}$ Nos referimos as categorias como conceitos que aparecem como nexos articuladores dos discursos. No que concerne a questão quilombola no Brasil as categorias "etnicidade" e "uso comum" se entrelaçam na interpretação dos agentes que atuam no Supremo Tribunal Federal durante o julgamento. Assim, "etnicidade" e "uso comum" fazem parte do pilar de argumentações que sustentam proposições de verdades de quem seriam as comunidades quilombolas e de quais seriam os seus direitos. No escrito os grupos étnicos e suas fronteiras, Barth (2000) esclarece que a etnicidade se refere a representação das diferenças entre grupos sociais, estruturadas com base em características
}

escravidão no país" (PETIÇÃO INICIAL

DA ADI No 3.239/2004, 2004, p. 10).

Já as manifestações voltadas para a defesa do Decreto $n^{\circ} 4.887 / 2003$ emitidas por agentes de peso no campo (o Advogado Geral da União e o Procurador Geral da República) usam como pilar de suas argumentações o conceito ressignificado de "quilombo", lançando mão das categorias "etnicidade", na chave oriunda de Barth (2000), e "uso comum" do território, tal como definida em Almeida (1989) ${ }^{5}$. Os argumentos de base jurídica se restringem no caso do primeiro, a aspectos procedimentais e no caso do segundo, a um uso não aprofundado da categoria "direito fundamental". Neste sentido, é possível apreender que a Manifestação da AGU segue um viés classificatório bem nítido, quando aponta a importância de se realizar "algumas aproximações de natureza antropológica (...) para então definir etnicamente quem são os remanescentes" (MANIFESTAÇÃO DA AGU, 2004, p.11). O texto, se contrapõe à Petição Inicial, que como sabemos, limitando-se a uma

atributivas e identificadoras empregadas pelos próprios sujeitos sociais. Seria a partir da interação com outros grupos e do estabelecimento de "fronteiras", que um determinado grupo passa a afirmar sua existência. Já a categoria "uso comum" do território, cunhada por Almeida (1989) indica uma modalidade da estrutura agrária brasileira que começou a ser mapeada a partir de 1986 e que define territórios que são conjuntamente exploradas por uma coletividade. Esta modalidade ganha denominações específicas de acordo com cada região e história: terras de santo, terras de pretos, terras de parentes, terras de índios, terras de herança entre outras. 
pespectiva histórico-cronológica, acabou se esquecendo da "transdiciplinaridade" do conhecimento. Com isso, a Manifestação chega ao segundo item: "A questão da identidade dos quilombos".

Apoiando-se em estudos antropológicos como os de Almeida (2002) e de O'dwyer (2002) - ambos, conhecidos articuladores na antropologia nacional do trabalho de "ressemantização" da categoria "quilombo" - o Advogado-Geral da União sustenta que o termo "remanescente das comunidades dos quilombos" possui difícil interpretação e tem gerado "mal-entendido". E isto porque, a aplicabilidade do Decreto $n^{\circ}$ 4.887/2003 dependeria do "método ou critério de identificação das comunidades quilombolas" (MANIFESTAÇÃO DA AGU, 2004, p.11). Um mês depois, a Manifestação do Procurador Geral da República (PGR) foi anexada aos autos do processo da ADI no 3239/2004. O documento apresenta parte do que fora alegado anteriormente pela Advocacia Geral da União (AGU), e de fato, não acrescenta elementos novos à interpretação sobre o caso.

Percebe-se ao longo dos autos do processo da ADI $n^{\circ}$ 3239/2004 que as categorias inseridas na interpretação jurídica foram buscadas majoritariamente em ambiente externo. Estas categorias carregariam uma legitimidade advinda do campo científico e sua inclusão no julgamento em tela operou alterações na própria lógica, que de maneira geral, informa a tomada de decisões no campo do direito. Mas no que diz respeito ao voto do relator da ADI o ministro Cesar Peluso manteve se a perspectiva de apontar uma separação radical entre a interpretação estritamente jurídica e os discursos externos, que este denominou como "metajurídicos". Peluso reconheceu a contribuição das ciências sociais para a compreensão do fenômeno "quilombola", mas foi taxativo em afirmar que tais estudos científicos não tinham qualquer relação com o julgamento em tela.

O ponto inicial da argumentação do Ministro Cezar Peluso, relator da ação, foi que o Decreto $\mathrm{n}^{\mathrm{o}} 4.887 / 2003$ seria inconstitucional por promover direta regulamentação do texto constitucional, o que não seria válido no ordenamento jurídico nacional. O relator mostra total concordância com a argumentação de matriz cronológica, que alicerça a Petição Inicial do PFL. Para o ministro Peluso, os "destinatários" do direito conferido pelo artigo 68 do ADCT:

São aqueles que subsistiam nos locais tradicionalmente conhecidos como quilombos, entendidos estes na acepção histórica, em 05 de outubro de 1988. Noutras palavras: os que, tendo buscado abrigo nesses locais (quilombos), antes ou logo após a abolição, lá permaneceram até a promulgação da Constituição de 1988 (ADI No 3.239/2004, VOTO RELATOR 1, 2012, p. 38). 
O relator se preocupa em apurar esta demarcação histórica, livrando-a de possíveis questionamentos. Por isso, afirma que não é necessário precisar a data da extinção formal da escravidão como o limite para a constituição dos quilombos, uma vez que naquele momento o país era marcado por grandes problemas de comunicação (daí o limite ser o ano de 1888). De fato, podemos entender que o ministro deve estar se referindo a possibilidade de uma hipotética fuga de escravos e consequente formação de um quilombo, ter ocorrido, por exemplo, em 13 de junho de 1888, um mês após a abolição e sem que escravos ou os senhores soubessem que aquele instituto não mais existia. Neste caso, os remanescentes do "quilombo" formado estariam também cobertos pelo artigo 68 do ADCT? Mas, por esta via, o mesmo não ocorreria caso o "quilombo" tivesse início em primeiro de janeiro de 1889 ? Quantos dias estão compreendidos no limite "logo após a abolição" (ADI No 3.239/2004, VOTO RELATOR 1, 2012, p. 38) definido no voto de Peluso? Vemos que a convicção do ministro é fruto, também, de uma interpretação. E esta não se afasta daquela que a Petição Inicial do PFL já levantara. A categoria "quilombo" que o voto do relator aponta como a acertada para a interpretação do artigo 68 do ADCT é de fundo cronológico

\footnotetext{
${ }^{6} \mathrm{O}$ pedido de vista é regulamentado no STF, e equivale a um período que o ministro examina melhor o processo antes de emitir seu voto. $\mathrm{O}$ regulamento interno do STF determina
}

e, portanto, os sujeitos do direito garantidos pela Constituição de 1988 seriam "remanescentes" de eventos que deveriam ter efetivamente ocorrido até o período imperial.

Após a exposição do voto do relator em 18 de abril de 2012, a ministra Rosa Weber solicitou vistas ${ }^{6}$ ao processo e este foi devolvido cinco dias depois, em 23 de abril de 2012. No entanto, o julgamento somente retornou a pauta em 25 de março de 2015 , quando a ministra então fez a leitura de seu voto. De acordo com a interpretação de Rosa Weber existiria um objeto claro no artigo 68 do ADCT: o direito dos remanescentes das comunidades de "quilombos" ao reconhecimento pelo Estado das terras por eles ocupadas. Isto leva a ministra a apontar que o direito territorial das comunidades quilombolas é um direito fundamental, dotado de eficácia plena e aplicação imediata. Rosa Weber concorda que o Decreto $\mathrm{n}^{\mathrm{o}}$ $4887 / 2003$ de fato regulamenta diretamente o artigo 68 do ADCT, e que este é o procedimento juridicamente correto, uma vez que tal artigo se refere à direito fundamental, que exige regulamentação imediata, e carrega elementos de autoaplicação. Em 25 de março de 2015, logo após a leitura do voto da ministra Rosa Weber, que "empatou" a votação da $\mathrm{ADI}$ n $^{\circ}$ 3.239/2004 no plenário do STF, o ministro Dias Toffoli pediu vistas ao

que o processo deve ser devolvido ao plenário duas sessões após aquela em que foi feito o pedido. 
processo. $\mathrm{O}$ voto deste ministro foi somente publicado no dia 9 de novembro de 2017. De acordo com o parecer de Dias Toffoli :

Não há dúvida de que o preceito constitucional motivou-se na necessidade de se reparar uma dívida histórica decorrente da injustiça secularmente praticada contra os negros desde o período escravocrata brasileiro. Trata-se de reparação concretizada no reconhecimento dos direitos de descendentes das comunidades dos antigos escravos à propriedade das terras por eles historicamente ocupadas. Indo mais além, garantiu a Carta da República, agora em seu texto permanente, a proteção das manifestações culturais afro-brasileiras (art. 215, $\S 1^{\circ}, \mathrm{CF}$ ) e o tombamento de todos os documentos e os sítios detentores de reminiscências históricas dos antigos quilombos (art. 216, § 5 , CF) (ADI $\mathrm{N}^{\circ} 3.239 / 2004$, VOTO MINISTRO TOFFOLI, 2017, p. 147).

Ainda segundo com o Ministro Dias Toffoli (2017) a “questão quilombola" está diretamente relacionada à identidade, à ação, à memória dos diferentes grupos formadores da sociedade brasileira - trata-se, portanto, da obrigação do Estado em resguardar o patrimônio material e imaterial brasileiro ao reconhecer direitos territoriais a grupos étnicos e minoritários. Todavia, não se pode deixar de reconhecer o caráter complexo deste panorama que tem suscitado interpretações divergentes "quanto ao alcance subjetivo e objetivo desse direito, bem como quanto às formas para sua

\footnotetext{
${ }^{7}$ Disponível

em: $\langle$ https://portal.stf.jus.br/processos/detalhe.asp?incident $\mathrm{e}=2227157$ > . Acesso em 11 jun. 2019.
}

aplicação, divergências essas das quais decorre, no meu sentir, o ajuizamento da presente ação direta de inconstitucionalidade" (ADI N $\mathrm{N}^{\mathrm{3}}$ 3.239/2004, VOTO MINISTRO TOFFOLI, 2017, p. 149). Tais questionamentos estão relacionados principalmente as seguintes questões:

Quem será beneficiado pela norma constitucional? Quem são os "remanescentes das comunidades dos quilombos"? Quais critérios utilizar para identificá-los? Quais terras serão objeto de titulação? Para ser reconhecido o direito de propriedade, em que momento a comunidade deveria "estar ocupando suas terras"? Esses pontos coincidem exatamente com as impugnações formuladas pelo partido autor da presente ação direta de inconstitucionalidade em face do Decreto federal $n^{\circ} 4.887$, de 20 de novembro de 2003 (ADI N ${ }^{\circ}$ 3.239/2004, VOTO MINISTRO TOFFOLI, 2017, P. 149).

Como se percebe, a interpretação construída pelo ministro deixou de lado a antiga definição de quilombo histórico, ao eleger critérios antropológicos para denominar o que seriam as comunidades quilombolas, e quais seriam os seus direitos na contemporaneamente. E esta foi também a posição da maioria dos ministros do STF no que diz respeito a ADI $n^{\circ} 3239 / 2004$. O inteiro teor do acórdão final ${ }^{7}$ deste julgamento foi publicado um ano depois do fechamento da ação, no dia 21 de fevereiro 
de 2019. Trata-se de um documento 353

(trezentas e cinquenta e três) páginas, que contém todo o discurso interpretativo dos ministros do STF, emitidos por meio dos votos proferidos sobre esta ação direta de inconstitucionalidade. Para abordamos profundamente tal questão precisaríamos de muitas páginas, já que se trata de um tema complexo. Mas em linhas gerais, podemos apontar que o julgamento final refutou todos os pontos apresentados pela Petição Inicial no que se refere ao Decreto $\mathrm{n}^{\circ}$ 4887/2003, ao propugnar que:

- o artigo 68 do ADCT é um dispositivo que traz claramente o titular do direito territorial (remanescentes das comunidades dos quilombos), o objeto do direito (terras por eles ocupadas), o conteúdo (direito de propriedade), a condição (ocupação tradicional), o sujeito passivo (Estado) e a obrigação específica (emissão de títulos), o que mostra que este dispositivo está apto a ser regulamento pelo Decreto n'4887/2003;

- a adoção da autoatribuição presente no Decreto n $4887 / 2003$ como critério de determinação da identidade é autorizado pela antropologia, e cumpre adequadamente aos destinatários do direito territorial quilombola, dado que a Convenção 169 da OIT sobre povos indígenas e tribais, da qual o Brasil é signatário, também referenda tal perspectiva. Esta condição deve ser garantida e respeitada, assim como a participação das comunidades quilombolas na medição $\mathrm{e}$ demarcação das terras durante o processo administrativo;

- existem outras países em que comunidades quilombolas tiveram o seu reconhecimento ao direito territorial atendidos o que mostra o compromisso destes estados com o direito de propriedade de comunidades formadas por descendentes de escravos fugitivos sobre as terras tradicionais com as quais mantêm relações territoriais, a exemplo dos casos de Moiwana v. Suriname (2005) e Saramaka v. Suriname;

- é necessário que o Estado cumpra a expropriação para a regularização das terras de quilombos que estão em posse de terceiros (BRASIL, ACORDÃO FINAL ADI No 3239/2004, 2019).

Durante o julgamento as discussões também foram posicionadas principalmente para a questão do marco temporal defendida pelo Partido Democratas e bancada ruralista durante todo o processo. São estes portanto, os pontos fundamentais da interpretação do campo jurídico brasileiro que tornou a Ação Direta de Inconstitucionalidade contra o direito territorial das comunidades quilombolas, improcedente, no dia 8 de fevereiro de 2018. O desfecho final desse embate foi desenhado com um placar de oito votos favoráveis ao direito territorial dos quilombolas - dos ministros Rosa Weber, Edson Fachin, Luís Roberto barroso, Ricardo Lewandowski, Luiz Fux, Marco Aurélio, Celso de Mello e Cármen Lúcia, e três votos contrários. 


\section{Considerações finais}

Neste artigo foi possível verificar como as performances discursivas no campo do direito vêm se articulando em torno de direitos territoriais, haja vista o reconhecimento das comunidades quilombolas como coletividades diferenciadas. O julgamento da ADI $n^{\circ}$ $3239 / 2004$ que se arrastou por 14 anos trouxe perplexidade e novas indagações ao campo do direito e à sociedade em geral ao colocar em cena questões relacionadas à garantia do direito fundamental à vida, a reprodução material, cultural, social e simbólica das comunidades quilombolas.

Entende-se que a garantia de acesso ou permanência ao território pelos povos e comunidades tradicionais como quilombolas está diretamente relacionado ao campo do direito na medida em que a efetividade destes depende do reconhecimento jurídico e étnico-racial legitimado pelos interlocutores que constituem este campo de forças e de construção de "verdades". Apesar da Constituição Federal de 1988 e do Decreto

\footnotetext{
${ }^{8}$ De acordo com o Supremo Tribunal Federal (2019) a Ação Direta de Inconstitucionalidade (ADI) tem por finalidade declarar que uma lei ou parte dela é inconstitucional, ou seja, contrária a Constituição Federal. Somente as seguintes pessoas/ entidades podem propor esta ação: Presidente da República; Mesa do Senado Federal; Mesa da Câmara dos Deputados; Mesa da Assembleia Legislativa ou da Câmara Legislativa do Distrito Federal; Governador de Estado ou do Distrito Federal; Procurador-Geral da República; Conselho Federal da Ordem dos Advogados do Brasil; Partido político com representação no Congresso Nacional;
}

$\mathrm{n}^{\text {o }} 4887 / 2003$ ter significado um grande avanço na legislação brasileira no que diz respeito aos direitos territoriais das comunidades quilombolas, este quadro tem ganhado um contorno preocupante - entre as ameaças de violação de direitos está a interpretação que vem sendo discutida e aplicada pelo Supremo Tribunal Federal (STF) denominada "marco temporal". Tal interpretação equivale a decisão do judiciário de reconhecer direitos territoriais somente de povos e comunidades tradicionais que estivessem ocupando as suas terras em 5 de outubro de 1988 (data da promulgação da Constituição Federal).

Neste âmbito, segundo Silva e Filho (2014) a tese do marco temporal que aparece em decisão plenária no julgamento da Petição/STF n ${ }^{\circ} .3388$ sobre a demarcação da Terra Indígena Raposa Serra do Sol tem sido aplicada em outras decisões do Supremo Tribunal Federal, tendo afetado processos de reconhecimento e demarcação de Terras Indígenas (TIs) de povos como os Terena, Guarani e Kaiowá. No que diz respeito à titulação de territórios quilombolas no julgamento final da ADI $n^{\text {o8 }} 3239 / 2004$ no

Confederação sindical ou entidade de classe no âmbito nacional. A tramitação da ADI inicia-se com uma Petição que deve apresentar fundamentos sobre a lei ou ato normativo inconstitucional. $\mathrm{O}$ ministro relator do processo deve solicitar maiores informações às autoridades de quem emanou a lei, tais como Presidente da República, Congresso Nacional, para estabelecer o contraditório. O Advogadogeral da União e o Procurador-Geral da República devem se manifestar nos autos, assim, como o amicus curiae (pessoa natural ou jurídica, órgão ou entidade especializada, com representatividade adequada que queira atuar na 
ano de 2018 contra o Decreto $n^{\circ}$ 4887/2003, o posicionamento da aplicação do marco temporal se mostrou superado pelo STF, apesar de ter sido levantado na arena de debates por alguns ministros do STF. Ainda de acordo com Silva e Filho (2004) as decisões do judiciário têm tentado relativizar os direitos territoriais dos povos e comunidades tradicionais a partir de um conjunto de propostas e alterações da Constituição na esfera legislativa com vistas a reduzir o poder da administração do executivo de reconhecer e demarcar terras indígenas e quilombolas.

Neste conjunto de tentativas da violação de direitos no Legislativo, podemos citar a Proposta de Emenda à Constituição (PEC) $n^{\circ} 215 / 2000$, que tem como principal objetivo a alteração do sistema de reconhecimento das Terras Indígenas, transferindo do Executivo para o Legislativo o poder de decisão final sobre as demarcações, entre outras medidas, como a abertura das terras indígenas a empreendimentos econômicos. Estas ações se aprovadas impactariam também comunidades quilombolas.

\section{Referências bibliográficas}

ALMEIDA, Alfredo Wagner Berno de. Terras de preto, terras de santo, terras de índio: uso comum e conflito. Belém: NAEA/UFPA, 1989.

ARRUTI, José Maurício. A emergência dos "Remanescentes": notas para o diálogo entre indígenas e quilombolas. Mana, Rio de Janeiro, v.3, n.2, out. 1997, p. 7-38.

Disponível em:

<http://www.scielo.br/scielo.php?pid=S010493131997000200001\&script=sci_arttext $>$. Acesso em : 4 jul. 2019

ARRUTI, José Maurício. Mocambo: antropologia e história do processo de formação quilombola. São Paulo: Edusc, 2006.

BRASIL. Decreto no 3.912, de 10 de setembro de 2001. Disponível em: $<$ http://www2.camara.leg.br/legin/fed/d ecret/2001/decreto-3912-10-setembro2001-395404-publicacaooriginal-1pe.html> Acesso em: 4 jul. 2019

\section{Ação Direta de}

Inconstitucionalidade $n^{\circ}$ 3.239-9 de 2004 em face do Decreto $n^{\circ} 4887 / 2003$. Brasília, DF, 2004. Disponível em:<http://www.cpisp.org.br/acoes/upload/ arquivos/Parecer\%20-\%20ProcuradorGeral\%20da\%20Rep\%C3\%BAblica.pdf> Acesso em: 5 jul. 2019

\section{Constituição da República}

Federativa do Brasil. Brasília, DF: Senado Federal: Centro Gráfico, 1988. 292 p. BRASIL.

\section{Decreto no 4887 de 20 de}

novembro de 2003. Regulamenta o procedimento para identificação,

encerrando-se assim a ADI através de um acórdão. Disponível

em: $<$ http://portal.stf.jus.br/processos/detalhe.asp?incidente $=2227157>$. Acesso em 07-06-2019. 
reconhecimento, delimitação, demarcação e titulação das terras ocupadas por remanescentes das comunidades dos quilombos de que trata o art. 68 do Ato das Disposições Constitucionais Transitórias. Presidência da República- Casa Civil. Brasília, DF, 2003. Disponível em: <http://www.planalto.gov.br/ccivil_03/decr eto/2003/D4887.htm> Acesso em: 10 jun. 2011.

\section{Inteiro teor do acordão final}

Adi no 3239/2004. Brasília: Supremo Tribunal Federal, 2018. Disponível em: $<$ http://redir.stf.jus.br/paginadorpub/pagina dor.jsp?docTP=TP\&docID=749028916>. Acesso em : 20 out. 2020.

BARTH, Fredrik. Os grupos étnicos e suas fronteiras. In: BARTH, Fredrik. O guru, o iniciador e outras variações antropológicas. Rio de Janeiro: Contra Capa Livraria, 2000.

BOURDIEU, Pierre. O poder simbólico. Tradução Fernando Tomaz. 6. ed. Rio de Janeiro: Bertrand Brasil, 2003.

\section{CONVENÇÃO Nacional do Negro pela}

Constituinte. Brasília: 26 e 27 de agosto de 1986. Disponível

em:<http://www.institutobuzios.org.br/docu mentos/CONVEN\%C3\%87\%C3\%830\%20 NACIONAL\%20DO\%20NEGRO\%20PEL A\%20CONSTITUTINTE\%201986.pdf> Acesso em: 10 jun. 2019.

\section{HARBELE, Peter. Hermenêutica}

Constitucional: A sociedade aberta dos intérpretes da Constituição: contribuição para a interpretação pluralista e 'procedimental' da Constituição. Tradução de Gilmar Ferreira Mendes. Porto Alegre: Sergio Antonio Fabris Editor, 1997.

O’DWYER, Eliane Cantarino (org).

Quilombos: identidade étnica e territorialidade. Rio de Janeiro: Editora da FGV, 2002.
SILVA. Liana Amin Lima da; FILHO, Carlos Frederico Marés de Souza. Marco temporal como retrocesso dos direitos territoriais originários indígenas e quilombolas. In: Direitos originários e territorialidade. Brasília: ANPR, 2018. Disponível em:

$<$ http://www.mpf.mp.br/atuacaotematica/ccr6/documentos-e publicacoes/artigos/docs_artigos/indiospdf. pdf $>$. Acesso em: 9 de fev. de 2019. 